\title{
Analysis and comparison of several urban road transportation assignment models in emergency conditions
}

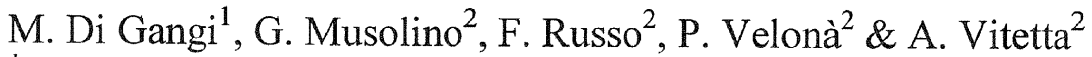 \\ ${ }^{I}$ Department of Architecture, Planning and Transport Infrastructure, \\ University of Basilicata, Italy. \\ ${ }^{2}$ Department of Computer Science, Mathematics, Electronics and \\ Transportation, Mediterranea University of Reggio Calabria, Italy.
}

\begin{abstract}
A large variety of models and procedures for road transportation system analysis exists in literature. The paper presents a comparison among different modelling approaches (pseudo dynamic, mesoscopic, microscopic) for the simulation of a road urban transportation system in emergency conditions.

Pseudo dynamic approach (derived from user equilibrium) can consider stochastic or deterministic user behaviour in path choice and is able to provide average values concerning traffic conditions.

The mesoscopic represents traffic conditions on the network analysing groups of drivers having homogeneous behaviours, called "packets". It provides results consistent with each packet.

According to the microscopic approach, it is possible to dynamically simulate each driver's behaviour and the interactions among drivers, tracking explicitly the space-time trajectory of each vehicle from origin to the destination.

The purpose of the research is to operate a comparative evaluation of potentialities, limits and domain of application of each approaches. An application on a test case, given by a small urban transportation system, is discussed, considering different demand and supply scenarios and a set of evaluation indicators.
\end{abstract}




\section{Environmental Health Risk}

\section{Introduction}

Few literature concerning the analysis of a transportation system in emergency conditions is present. In [1], it is faced the definition of path choice sets for pedestrian evacuation in pubblic buildings, by means of a dynamic network loading model of demand flows on the network; in [2], evacuation times by means of a mesoscopic approach in the Vesuvio volcano area are estimated; [3] and [4] present a pseudo dynamic approach for the demand management at departure time and distribution dimensions for the evacuation of the population from an urban area; in [5] and [6], general models and procedures to be used in a "what if" and "what to" approach of road transportation network analysis in emergency conditions are described and classified.

Models and procedures described in [4], [7], [8] are applied to simulate the evacuation of the town of Zafferana Etnea, Italy. For every approach, the applications highlight advantages and disadvantages. The pseudo dynamic approach is based on the static approach concepts and it can be applied with commercial software, but it does not simulates explicitly the interaction among vehicles and the queues formation and dissipation phenomena. It allows to execute a general analysis of the transportation system in emergency conditions and to support the design of an evacuation plan. The mesoscopic approach allows the analysis in real time of the traffic flow conditions and the simulation of queues formation and dissipation; on the other side, the analysis is aggregate for group of drivers (packets). Finally, the microscopic approach allows the simulation of queues formation and dissipation and allows disaggregate analysis for each driver; but it needs high computation times for extended transportation networks and large amount of data for the behavioural rules definition.

\section{Applications}

The applications are carried out on the town of Zafferana Etnea in order to compare the results obtained from a pseudo dynamic assignment with those obtained from dynamic assignment models with mesoscopic and microscopic specification.

\subsection{The town of Zafferana Etnea}

The examined road transportation network of the town of Zafferana Etnea has 30 nodes ( 8 origins and 4 assembly centres, located on the border of the area), 61 road links (Figure 1).

Concerning the demand (2000 vehicles), two assumptions are made for the demand flow distribution towards the assembly centres: uniform demand distribution $(U)$, the drivers are equally distributed from each origin among all the available assembly centres; not uniform demand distribution $(N)$, the drivers 
are distributed among the available assembly centres according to their capacities and to their distance from the origin.

In order to analyse and compare the network performances, the following indicators are defined: total travel time on the network $\left(\mathrm{T}_{\mathrm{tot}}\right)$, total travel distance on the network $\left(\mathrm{L}_{\mathrm{tot}}\right)$, evacuation time or time at which the last vehicle evacuates from the network $\left(\mathrm{t}_{\mathrm{lve}}\right)$, average travel time on the network $\left(\mathrm{T}_{\mathrm{a}}\right)$, average speed on the network $\left(\mathrm{V}_{\mathrm{a}}\right)$.

The simulations are executed assuming different demand distributions scenarios, according to Table 1.

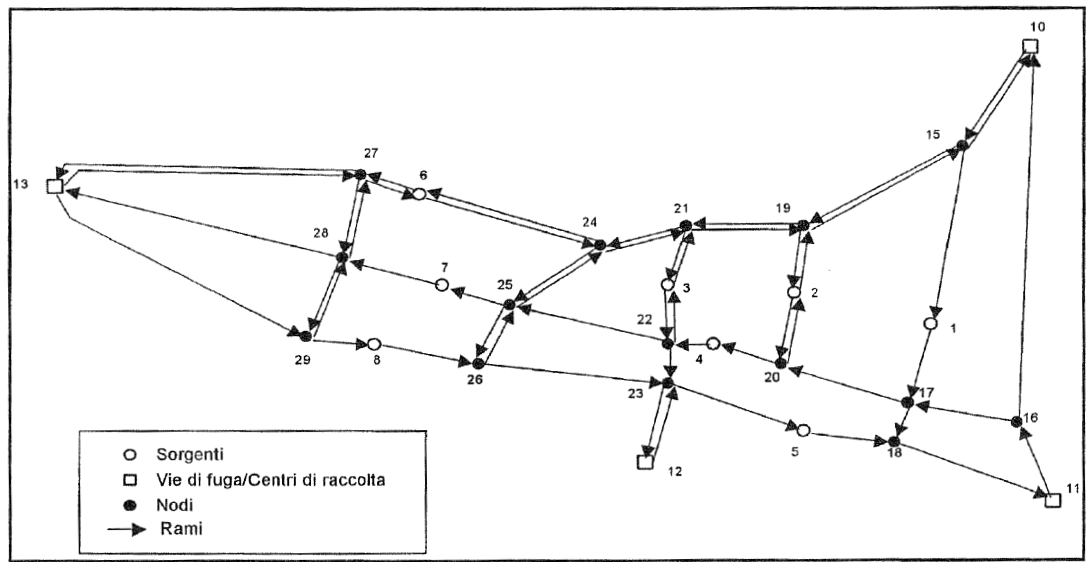

Figure 1: The town of Zafferana Etnea.

Table 1: Set of the demand and supply scenarios.

\begin{tabular}{ccccc}
\hline Scenarios & Num. assembly centres & Nodes* & \multicolumn{2}{c}{ Demand Distribution } \\
\hline 1 & 3 & $10,11,12$ & $\mathrm{U}$ & $\mathrm{N}$ \\
2 & 3 & $11,12,13$ & $\mathrm{U}$ & $\mathrm{N}$ \\
3 & 3 & $10,12,13$ & $\mathrm{U}$ & $\mathrm{N}$ \\
4 & 4 & $10,11,12,13$ & $\mathrm{U}$ & $\mathrm{N}$ \\
\hline
\end{tabular}

* see figure 1

\subsection{Applications with pseudo dynamic approach}

The static assignment simulates the travel time on the link taking into account two components, the running time on the link and the waiting time at the final node. The assumptions that usually characterize this approach are: stationary and stable traffic flow conditions.

The queue formation and dissipation phenomena are not represented. In order to take into account the effects of these phenomena on travel time, parameters of a cost function are calibrated on the base of travel times obtained, as an example, 


\section{Environmental Health Risk}

with a mesoscopic simulator able to represent also congested traffic flow conditions.

Table 2 presents the values of the indicators for every scenario, considering the two demand distributions among the assembly centers and taking into account the time for the queue formation and dissipation.

The not uniform distribution, which selects the assembly centres from each origin, allows to reduce the evacuation times respect to uniform distribution. This does not imply that the selection of the nearest assembly centres from each origins ensures lowest evacuation times. Moreover, the increase of the number of assembly centres does not cause the reduction of the evacuation time.

It is evident that the definition of the best scenario comes out only for the simulation, taking into account the supply and the demand and their interaction. So, the management of emergency conditions and the evacuation of an urban area, necessarily must be supported by quantitative analyses.

Table 2 shows the evacuation time, the aliquots of the simulation time and of the maximum travel time between an origin and an assembly centre.

Table 2: Indicators for the defined scenarios and relative variations.

\begin{tabular}{cccccc}
\hline Scenario Distribution & $\begin{array}{c}\mathrm{T}_{\text {tot }} \\
{[\text { veic } \mathrm{h} \mathrm{h}]}\end{array}$ & $\begin{array}{c}\mathrm{L}_{\mathrm{tot}} \\
{[\text { veic } \mathrm{km}]}\end{array}$ & $\begin{array}{c}\mathrm{T}_{\mathrm{lve}} \\
{[\mathrm{min}]}\end{array}$ & $\begin{array}{c}\mathrm{V}_{\mathrm{a}} \\
{[\mathrm{km} / \mathrm{h}]}\end{array}$ \\
\hline \multirow{2}{*}{1} & $\mathrm{U}$ & 235 & 2668 & $44(30+14)$ & 20.5 \\
& $\mathrm{~N}$ & 202 & 2469 & $35(25+10)$ & 19.9 \\
& $\Delta$ & $14.04 \%$ & $7.46 \%$ & $20.45 \%$ & $2.93 \%$ \\
\hline \multirow{2}{*}{2} & $\mathrm{U}$ & 235 & 2894 & $46(30+16)$ & 23.1 \\
& $\mathrm{~N}$ & 169 & 1771 & $27(21+6)$ & 18.6 \\
& $\Delta$ & $28.09 \%$ & $38.80 \%$ & $41.30 \%$ & $19.48 \%$ \\
\hline \multirow{3}{*}{3} & $\mathrm{U}$ & 201 & 2963 & $31(19+12)$ & 20.4 \\
& $\mathrm{~N}$ & 184 & 2167 & $24(15+9)$ & 14.6 \\
& $\Delta$ & $8.46 \%$ & $26.86 \%$ & $22.58 \%$ & $28.43 \%$ \\
\hline \multirow{2}{*}{4} & $\mathrm{U}$ & 220 & 2905 & $41(25+16)$ & 22.6 \\
& $\mathrm{~N}$ & 155 & 1685 & $26(18+8)$ & 17.2 \\
& $\Delta$ & $29.55 \%$ & $42.00 \%$ & $36.59 \%$ & $23.89 \%$ \\
\hline
\end{tabular}

$\mathrm{U}$, uniform demand distribution; $N$, not uniform demand distribution, $\Delta=100(\mathrm{U}-\mathrm{N}) / \mathrm{U}$

\subsection{Applications with mesoscopic approach}

In order to make this application more comparable with the pseudo-dynamic one, the considered speed-density relationships have been derived from the BPR functions [9] used in pseudo-dynamic simulation. The length of each simulation period has been fixed in 300 seconds. Some simulations have been performed for different departures times. Setting different number of departure time intervals, different evacuation times have been obtained; table 3 shows that, when the 
number of departure time intervals increases, the evacuation time, generally, reduces until it reaches a limit value beyond which the evacuation time increases. This is due to the fact that, splitting departures in time, the rise of evacuation time due to the queues, is less significant. With an excessive number of departure time intervals, the network is not congested and this implies an increment of the evacuation time due to a not necessary putting off of departures. Table 4 presents the values of the obtained indicators for every simulated scenario.

Figure 2 presents, for different scenarios, the time profiles of queued vehicles on an access link to an assembly centre. From these diagrams, it is showed the difference between the case of uniform and not uniform demand distributions.

In the first case there is a higher number of queued vehicles with an increasing travel time and, consequently, final evacuation time. In the scenario 3 , node 11 is not an assembly centre, so link 18-11 (see Figure 1) is unloaded or it is used by vehicles that must reach another assembly centre. It is evident that for scenario 3 , where link 18-11 is a crossing link and is not an access link to an assembly centre, for uniform demand distribution, there are not queued vehicles for all the simulation time; in truth, the link is crossed by vehicles but the flow conditions do not cause queues formation.

Table 3: Evacuation times [min] for different scenarios.

\begin{tabular}{cccccccc}
\hline \multirow{2}{*}{ Scenarios } & \multicolumn{7}{c}{ Departure time intervals } \\
\hline \multirow{2}{*}{1} & $\mathrm{U}$ & 44 & 43 & 40 & 39 & 39 & 40 \\
& $\mathrm{~N}$ & 45 & 36 & 35 & 34 & 34 & 38 \\
2 & $\mathrm{U}$ & 44 & 43 & 40 & 43 & 42 & 45 \\
& $\mathrm{~N}$ & 35 & 30 & 29 & 28 & 30 & 34 \\
3 & $\mathrm{U}$ & 34 & 31 & 28 & 29 & 32 & 37 \\
& $\mathrm{~N}$ & 36 & 28 & 27 & 27 & 31 & 35 \\
4 & $\mathrm{U}$ & 36 & 34 & 35 & 35 & 37 & 38 \\
& $\mathrm{~N}$ & 31 & 30 & 25 & 26 & 28 & 33 \\
\hline
\end{tabular}

$\mathrm{U}$, uniform demand distribution; $\mathrm{N}$, not uniform demand distribution.

Table 4: Indicators for the defined scenarios and relative variations.

\begin{tabular}{cccccc}
\hline Scenario & Distribution & $\begin{array}{c}\mathrm{T}_{\text {tot }} \\
\text { [veic X h] }\end{array}$ & $\begin{array}{c}\mathrm{L}_{\text {tot }} \\
{[\text { veic x km] }}\end{array}$ & $\begin{array}{c}\mathrm{t}_{\text {lve }} \\
{[\mathrm{min}]}\end{array}$ & $\begin{array}{c}\mathrm{V}_{\mathrm{a}} \\
{[\mathrm{km} / \mathrm{h}]}\end{array}$ \\
\hline \multirow{2}{*}{1} & $\mathrm{U}$ & 335 & 2584 & 40 & 20.2 \\
& $\mathrm{~N}$ & 342 & 2366 & 35 & 20.3 \\
& $\Delta$ & $-2 \%$ & $8 \%$ & $13 \%$ & $0 \%$ \\
\hline \multirow{3}{*}{2} & $\mathrm{U}$ & 338 & 2714 & 40 & 20.6 \\
& $\mathrm{~N}$ & 254 & 1637 & 29 & 20.8 \\
& $\Delta$ & $25 \%$ & $40 \%$ & $28 \%$ & $-1 \%$ \\
\hline \multirow{3}{*}{3} & $\mathrm{U}$ & 239 & 2882 & 28 & 21 \\
& $\mathrm{~N}$ & 215 & 2154 & 27 & 20.6 \\
& $\Delta$ & $10 \%$ & $25 \%$ & $4 \%$ & $2 \%$
\end{tabular}


252 Environmental Health Risk

\begin{tabular}{cccccc}
\hline \multirow{4}{*}{4} & $\mathrm{U}$ & 257 & 2803 & 35 & 22.1 \\
& $\mathrm{~N}$ & 183 & 1674 & 25 & 20.5 \\
& $\Delta$ & $29 \%$ & $40 \%$ & $29 \%$ & $7 \%$ \\
\hline U, uniform demand distribution; $\mathrm{N}$, not uniform demand distribution, $\Delta=100(\mathrm{U}-\mathrm{N}) / \mathrm{U}$
\end{tabular}

Link (18-11) - ass embly center 11

Link (18-11) - assembly center 11

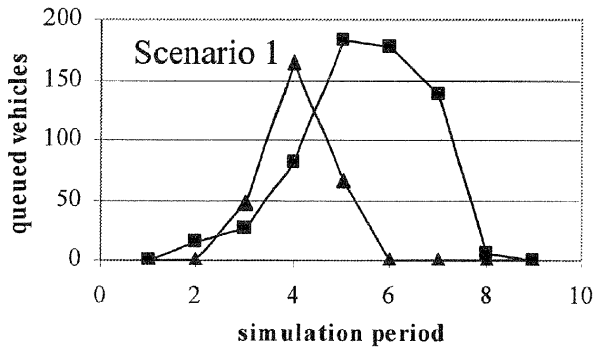

Link (18-11) - ass embly center 11

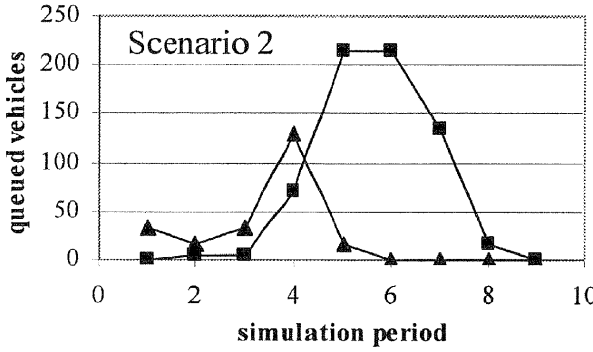

Uniform distribution

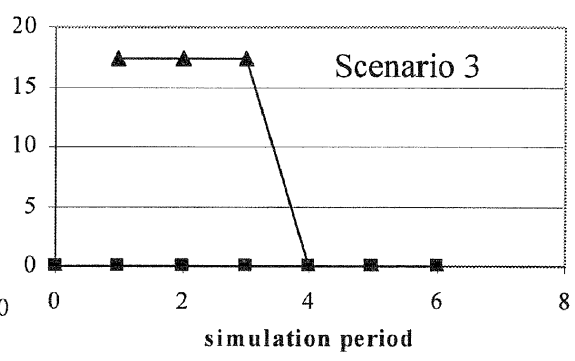

Link (18-11) - assembly center 11

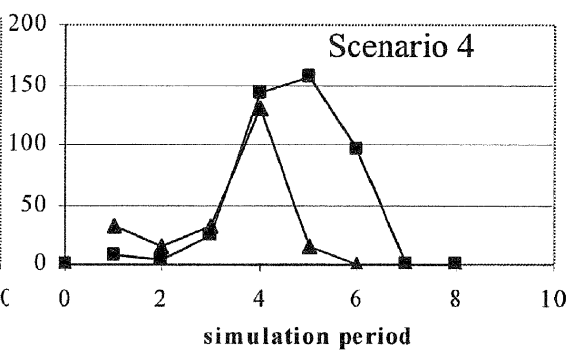

Not Uniform distribution

Figure 2: Time profiles of queued vehicles on the access link 18-11 to the assembly centre 11 for 4 scenarios.

\subsection{Applications with microscopic approach}

The considered traffic flow models are a car-following model and a lanechanging model on the link and a gap-acceptance model at the node [8].

Table 5 presents the values of the defined indicators for every simulated scenario, considering the two demand distributions. For the not uniform demand distribution, the values of the indicators are always inferior than the values obtained for the uniform demand distribution. Such evidence shows that, in order to obtain better performances of the transportation system, the supply modifications are not sufficient, but it is necessary to manage the demand distribution among the assembly centres.

Moreover, from the comparison of the different scenarios, scenario 4 provides the best average performances, because of the 4 available assembly centres, both for uniform and not uniform demand distributions; however, in the latter case the 
evacuation time of scenario 3 presents a lower value $\left(t_{\mathrm{lve}}=24.16 \mathrm{~min}\right)$ than the value of scenario $4\left(\mathrm{t}_{\mathrm{lve}}=26.33 \mathrm{~min}\right)$.

Figure 3 show the number of evacuated vehicles (vehicles that reached the assembly centers) at discrete time intervals of 3 minutes for scenarios $1,2,3,4$.a respectively.

The graphical results highlight that number of evacuated vehicles for the not uniform demand distribution is always higher than the one related to the uniform distributions for each time interval, confirming the better performances of the network in the former case.
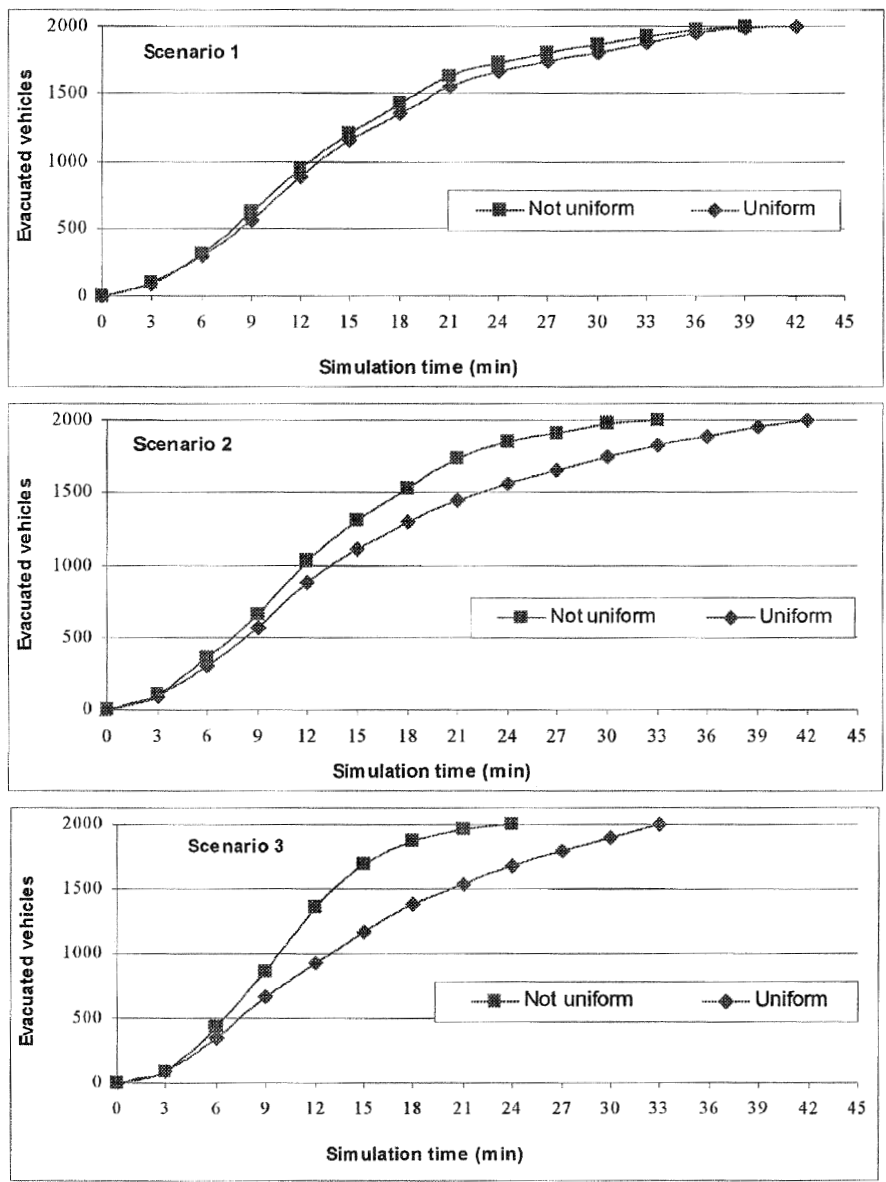
254 Environmental Health Risk

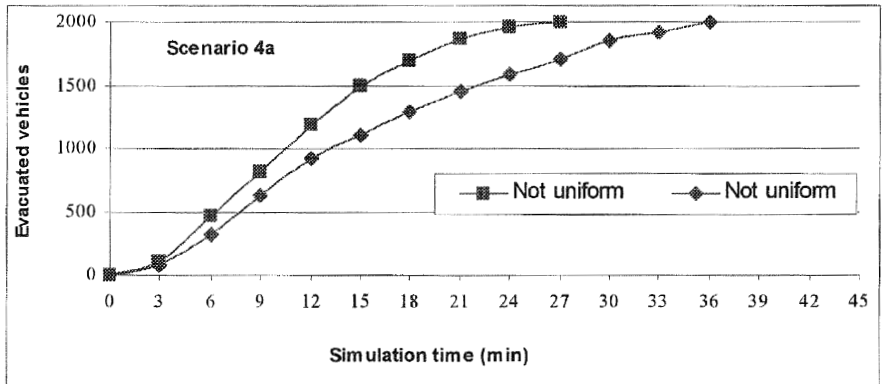

Figure 3: Total number of evacuated vehicles for 4 scenarios.

Table 5: Indicators for the defined scenarios and relative variations.

\begin{tabular}{|c|c|c|c|c|c|}
\hline Scenario & Distribution & $\begin{array}{c}\mathrm{T}_{\text {tot }} \\
{[\text { veic } \times \mathrm{h}]}\end{array}$ & $\begin{array}{c}\mathrm{L}_{\text {tot }} \\
\text { [veic } \times \mathrm{km}]\end{array}$ & $\begin{array}{c}\mathrm{t}_{\mathrm{lve}} \\
{[\mathrm{min}]}\end{array}$ & $\begin{array}{c}V_{\mathrm{a}} \\
{[\mathrm{km} / \mathrm{h}]}\end{array}$ \\
\hline \multirow{3}{*}{1} & $\mathrm{U}$ & 320.7 & 2910 & 42.5 & 15.43 \\
\hline & $\mathrm{N}$ & 363.8 & 2717 & 41.6 & 12.70 \\
\hline & $\Delta$ & $-13.44 \%$ & $6.63 \%$ & $2.12 \%$ & $17.69 \%$ \\
\hline \multirow{3}{*}{2} & $\mathrm{U}$ & 328.9 & 3113 & 42.3 & 16.1 \\
\hline & $\mathrm{N}$ & 282.1 & 1862 & 35.5 & 11.2 \\
\hline & $\Delta$ & $14.23 \%$ & $40.19 \%$ & $16.08 \%$ & $30.43 \%$ \\
\hline \multirow{3}{*}{3} & $\mathrm{U}$ & 308.3 & 3183 & 34.6 & 17.6 \\
\hline & $\mathrm{N}$ & 238.7 & 2131 & 24.16 & 15.18 \\
\hline & $\Delta$ & $22.58 \%$ & $33.05 \%$ & $30.17 \%$ & $13.75 \%$ \\
\hline \multirow{3}{*}{$4 a^{*}$} & $\mathrm{U}$ & 279.1 & 2966 & 34.6 & 18.07 \\
\hline & $\mathrm{N}$ & 218.3 & 1658 & 26.33 & 12.92 \\
\hline & $\Delta$ & $21.78 \%$ & $44.10 \%$ & $23.90 \%$ & $28.50 \%$ \\
\hline \multirow{3}{*}{$4 b^{* *}$} & $\mathrm{U}$ & 283.2 & 2958 & 28.66 & 17.76 \\
\hline & $\mathrm{N}$ & 220.6 & 1655 & 26.6 & 12.76 \\
\hline & $\Delta$ & $22.10 \%$ & $44.05 \%$ & $7.19 \%$ & $28.15 \%$ \\
\hline
\end{tabular}

$\mathrm{U}$, uniform demand distribution; $\mathrm{N}$, not uniform demand distribution, $\Delta=100(\mathrm{U}-\mathrm{N}) / \mathrm{U}$

* with priority rules at the nodes, ${ }^{* *}$ without priority rules at the nodes.

\subsection{Comparison among the approaches}

Tables 2,4 and 5 show that, generally, the values of $t_{1 v e}$ for the scenarios with uniform demand distribution are greater than the ones for scenarios with not uniform demand distrubution. This evidence, as previously said, confirm the necessity to modify not only the supply but also the demand, as for example the demand distribution dimension.

Table 6 shows the relative differences of the indicators from the comparison of the approaches.

Comparing meso and pseudo approaches, $\mathrm{t}_{\mathrm{ve}}$ is greater in the pseudo approach 
in five cases, while $T_{a}$ is greater in the meso approach. Such discrepancy is caused from the different path choice set definition. In meso approach drivers have a higher travel time respect to pseudo, because the perceived paths are defined through a pre-elaboration of a perceived choice set procedure and some paths with high congestion are used. This situation determines a lower value of $\mathrm{t}_{\mathrm{lvc}}$ in a high number of simulated scenarios.

Comparing micro and meso approaches, $\mathrm{t}_{\mathrm{lve}}$ and $\mathrm{L}_{\mathrm{tot}}$ are higher in micro for scenarios 1 e 2 , because of a different traffic representation: micro approach simulates every single vehicle, while meso approach simulates groups of vehicles. This difference determines an underestimation of the queues formation and dissipation and of interaction between vehicles phenomena from the meso approach. In scenarios 3 e 4 congestion is lower than in scenarios 1 e 2 , so the effects of the underestimation are not so evident.

Moreover, in micro approach the path choice is updated at discrete intervals, causing the choice of less istantaneously congested paths with a greater extension in same cases; while in meso approach paths have been defined as the same of those obtained in pseudo-dynamic approach and are not updated during the simulation time.

Table 6: Comparison among the approaches. Relative values.

\begin{tabular}{|c|c|c|c|c|c|c|c|c|c|c|}
\hline \multirow[b]{2}{*}{ Scen. } & \multirow[b]{2}{*}{ Distrib. } & \multicolumn{3}{|c|}{ Meso-Pseudo } & \multicolumn{3}{|c|}{ Micro-Meso } & \multicolumn{3}{|c|}{ Pseudo-Micro } \\
\hline & & $\Delta \mathrm{t}_{\text {lve }}$ & $\Delta \mathrm{L}_{\text {tot }}$ & $\Delta \mathrm{T}_{\mathrm{a}}$ & $\Delta t_{\mathrm{ve}}$ & $\Delta \mathrm{L}_{\text {tot }}$ & $\Delta \mathrm{T}_{\mathrm{a}}$ & $\Delta t_{\mathrm{lve}}$ & $\Delta \mathrm{L}_{\text {tot }}$ & $\Delta \mathrm{T}_{\mathrm{a}}$ \\
\hline \multirow{3}{*}{1} & U & $-10.0 \%$ & $-3.2 \%$ & $30.0 \%$ & $5.9 \%$ & $11.2 \%$ & $-4.5 \%$ & $3.4 \%$ & $-9.1 \%$ & $-36.7 \%$ \\
\hline & $\mathrm{N}$ & $0.0 \%$ & $-4.3 \%$ & $41.2 \%$ & $15.9 \%$ & $12.9 \%$ & $6.4 \%$ & $-18.8 \%$ & $-10.1 \%$ & $-81.7 \%$ \\
\hline & U & $-15.0 \%$ & $-6.6 \%$ & $30.7 \%$ & $5.4 \%$ & $12.8 \%$ & $-2.5 \%$ & $8.1 \%$ & $-7.6 \%$ & $-40.7 \%$ \\
\hline \multirow[t]{2}{*}{2} & $\mathrm{~N}$ & $6.9 \%$ & $-5.1 \%$ & $34.2 \%$ & $18.3 \%$ & $12.1 \%$ & $10.6 \%$ & $-31.5 \%$ & $-8.2 \%$ & $-70.0 \%$ \\
\hline & U & $-10.7 \%$ & $-2.8 \%$ & $16.7 \%$ & $19.1 \%$ & $9.4 \%$ & $21.9 \%$ & $-11.6 \%$ & $-7.4 \%$ & $-53.7 \%$ \\
\hline \multirow[t]{2}{*}{3} & $\mathrm{~N}$ & $11.1 \%$ & $-0.6 \%$ & $14.1 \%$ & $-11.7 \%$ & $-1.1 \%$ & $10.6 \%$ & $-0.7 \%$ & $1.7 \%$ & $-30.2 \%$ \\
\hline & U & $-17.1 \%$ & $-3.6 \%$ & $12.9 \%$ & $-1.2 \%$ & $5.5 \%$ & $8.7 \%$ & $15.6 \%$ & $-2.1 \%$ & $-25.8 \%$ \\
\hline 4 & $\mathrm{~N}$ & $-4.0 \%$ & $-0.7 \%$ & $16.4 \%$ & $5.1 \%$ & $-0.9 \%$ & $15.9 \%$ & $-1.3 \%$ & $1.6 \%$ & $-42.2 \%$ \\
\hline
\end{tabular}

$\mathrm{U}$, uniform demand distribution; $\mathrm{N}$, not uniform demand distribution.

The three approaches provide similar results in relation to the evacuation indicators considered but each of them has some specific characteristics.

In the different simulated scenarios, on average, the pseudo approach gives higher $\mathrm{t}_{\text {lve }}$ but lower $\mathrm{L}_{\text {tot }}$. With pseudo approach drivers take more time to evacuate but they consider the shortest length paths.

Differences among approaches are connected also with the demand distribution considered because the relative values in scenario 4, where all assembly centres are active, are different in magnitude and in some cases also in sign respect scenarios 1,2 e 3 , where three assembly centres are active. 


\section{Environmental Health Risk}

\section{Conclusive remarks}

In this paper some results concerning a comparison among different approaches, both static and dynamic, to simulate the evacuation of an urban area have been reported.

A critical analysis of these results allows to underline two aspects analyzed in the following.

The first one concerns the comparison itself: in authors' knowledge there is no other example in literature where results obtained from both static and dynamic modeling approaches on the same test network are simultaneously compared. Results of this comparison show how, on one side, a static approach can be used to perform a first analysis to obtain a level of magnitude of the time needed for evacuation and of network capabilities, on the other side, a deeper investigation on network capabilities and critic situations needs a dynamic approach.

Concerning dynamic assignment models, even if microscopic approach is able to describe with a significant level of detail and reliability traffic conditions, at the time being it seems to be more suitable for the simulation of relative small areas, since the amount of computing resources (and time needed for simulation) largely increases with the dimension of the problem in terms of network extension and number of vehicles. Real time applications on real networks, here not reported, suggest that the more is the size of the considered area the more a mesoscopic approach seems more suitable and efficient in terms of time of execution, resources and calibration of parameters than microscopic approach.

The second aspect to be underlined concerns the purpose which the assignment models are developed for. As a matter of fact, in the last years, it raised the need to apply assignment models to support logistic problems connected with risk analysis and disaster management. So, many efforts are going to be spent in order to adapt and/or formulate assignment models to satisfy the needs of such applications.

Some of the models here described seem to be well suitable for these purposes, in particular static ones for the design (what to) and dynamic ones for the simulation (what if).

\section{References}

[1] Adamo V., Astarita V. \& Polidoro R., La simulazione dinamica dei flussi pedonali: metodologie ed applicazioni per il calcolo dei transitori nello svuotamento delle aree e strutture affollate. ISCS Conference. Roma, 1996.

[2] Di Gangi M., Luongo A. \& Polidoro R., Una procedura di carico dinamico per la valutazione dei piani di evacuazione. In Metodi e Tecnologie dell'Ingegneria dei Trasporti. Seminario 1999, a cura di G.E. Cantarella e F. Russo, FrancoAngeli, 2001.

[3] Velonà, P. \& Vitetta, A., Procedure di assegnazione pseudo dinamica per la valutazione del tempo di evacuazione di una rete di trasporto. Atti del Convegno INPUT 2001. Isole Tremiti, 2001. 
[4] Velonà, P. \& Vitetta, A., Evolution of an urban transportation system in emergency conditions: analysis through a pseudo-dynamic assignment model. In this book, 2003.

[5] Russo, F. \& Vitetta, A., Urban road transportation analysis in emergency conditions: models and algorithms. Proceedings of Urban Transport 2000, Wessex Institute of Technology. Sucharov and Brebbia ed., WIT Press Boston, pp. 533-542, 2000.

[6] Russo, F. \& Vitetta, A., Urban transportation system analysis in emergency conditions. In this book, 2003.

[7] Di Gangi, M. \& Velonà, P., Use a mesoscopic dynamic assignment model for approaching the evolution of an urban transportation system in emergency conditions. In this book, 2003.

[8] Musolino, G. \& Vitetta, A., Microscopic approach for the evaluation of an urban transportation system in emergency conditions. In this book, 2003.

[9] Branston, D., Link capacity functions: A review. Transportation Research, Vol.10B, 223-236, 1976. 
